Jurnal Geografi, Edukasi dan Lingkungan (JGEL) Vol. 4, No. 1, Januari 2020:8-16

P-ISSN: 2579-8499; E-ISSN: 2579-8510

Doi: https://doi.org/10.29405/jgel. v4i1.3640

Website: http://journal.uhamka.ac.id/index.php/jgel

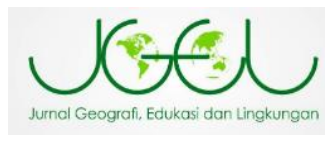

\title{
Analisis Perubahan Penggunaan Lahan Pasca Kejadian Tsunami Tahun 2018 Sebagai Rekomendasi Tata Ruang Di Pesisir Pantai Kecamatan Panimbang, Pandeglang, Banten
}

\author{
Siti Dahlia*, Agung Adiputra, Alwin, M. Aji Najiyullah, Kamzia, dan Fakhri \\ Kurnia Rahmadiansyah \\ Pendidikan Geografi, FKIP Universitas Muhammadiyah Prof. DR. Hamka, Jakarta \\ Timur, Indonesia
}

*E-mail: sitidahlia@uhamka.ac.id

Received: 26082019 / Accepted: 17122019 / Published online: 30012020

\begin{abstract}
ABSTRAK
Area Selat Sunda memiliki risiko terhadap bencana tsunami akibat aktivitas erupsi Anak Gunung Krakatau. Pada Desember Tahun 2018 terjadi silent tsunami akibat runtuhan material erupsi Anak Krakatau, yang berdampak pada kerusakan di pesisir Kecamatan Panimbang. Berdasarkan hal tersebut, penelitian ini bertujuan untuk memetakan perubahan lahan sebelum dan pasca kejadian tsunami tahun 2018, dan analisis tata ruang wilayah Pesisir Panimbang berbasis bencana tsunami. Metode untuk memetakan perubahan penggunaan lahan yaitu identifikasi penggunaan lahan wilayah penelitian sebelum dan sesudah terjadi tsunami Desember Tahun 2018 berbasis data Citra Googel Earth dan Sentinal, dengan metode interpretasi citra. Selain itu, penggunaan lahan pasca tsunami di identifikasi dengan metode survei lapangan menggunakan alat drone, dan GPS. Untuk memvalidasi informasi dilakukan wawancara mendalam dengan Masyarkat setempat. Metode untuk analisis tata ruang dengan cara melakukan review Rencana Tata Ruang Wilayah (RTRW) Kabupaten Pandegelang, secara struktur dan pola ruang. Hasil penelitian menunjukkan bahwa adanya perubahan penggunaan lahan wilayah penelitian, khususnya diarea pesisir Panimbang. Perubahan yang terjadi teridentifikasi adanya kawasan pemukiman yang hilang, kawasan wisata dan resort yang rusak, dan memunculkan adanya kawasan Hunian Sementara. Desa yang mengalami signifikan perubahan yaitu Desa Tanjungjaya. Berdasarkan peninjauan Peraturan Daerah Kabupaten Pandeglang No. 3 Tahun 2011 wilayah penelitian merupakan kawasan konservasi mangrove, bencana banjir, pertanian dan perikanan, wisata, dan kawasan strategis pertumbuhan ekonomi, dan kawasan startegis kabupaten. Berdasarkan hal tersebut, tidak teridentifikasi wilayah penelitian sebagai kawasan bencana geologis atau rawan tsunami, untuk itu tidak tergambarkan rencana tata ruang wilayah penelitian berbasis tsunami.
\end{abstract}

Kata Kunci: Penggunaan Lahan, Tsunami, dan Rencana Tata Ruang Wilayah

\section{ABSTRACT}

The Selat Sunda area has a risk of tsunami due to the eruption of Anak Krakatau Mountain. In December 2018, there was a silent tsunami caused by eruption material of the Anak Krakatau. Based on this, this study aims to maping of landuse changes before and after the 2018 tsunami event, and analyze the spatial plan of the Panimbang area 
based on the tsunami disaster. The method for mapping land use change is the identification of land use in the study area before and after the December 2018 tsunami based on Googel Earth and Sentinal imagery data, with the interpretation method. In addition, post-tsunami land use was identified by the field survey method using drones and GPS. In order to validate the information an in-depth interview was conducted with the local community. The method for spatial plan analysis is by conducting a review of Rencana Tata Ruang Wilayah (RTRW) Pandegelang District, in terms of structure and pattern spatial. The results showed that there was a change in the land use of the study area, especially in the Panimbang coastal area. It was many of residential area removed, damaged tourist and resorts areas, and there are build up of Temporary Residential Areas. The village that experienced significant changes was Tanjungjaya Village. Based on the review of Pandeglang District Regulation No. 3 of 2011 the research area is a mangrove conservation area, flood disaster, agriculture and fisheries, tourism, and a strategic area of economic growth, and strategic district area. Based on this, the research area was not identified the spatial plan for tsunami hazard.

Keywords: Landuse Change, Tsunami, and Spatial Plan

\section{PENDAHULUAN}

Indonesia sebagai negara kepulauan secara geologis rentan terhadap bencana alam pesisir yaitu tsunami. Tsunami merupakan gelombang laut yang dihasilkan oleh proses geologi bawah laut berupa letusan gunungapi, gempa bumi, longsoran serta jatuhnya meteor di laut (Surmayadi, 2012).

Data historis kejadian tsunami akibat tektonik di pesisir Selatan Pulau Jawa yaitu 4 Januari 1840, 20 Oktober 1859, 11 September 1921, dan 17 Juli 2006 (Yudhicara \& Budiono, 2008). Selain faktor tektonik, tsunami di Pulau Jawa disebabkan olah faktor vulkanik sebagai contoh pada 27 Agustus 1883 tsunami yang disebabkan oleh erupsi gunung Krakatau.

Di wilayah pesisir tsunami dapat menimbulkan korban jiwa, menghancurkan perumahan, pusat komersial, pertanian, dan perikanan (Tejakusuma, 2005). Hal ini dapat disebabkan karena gelombang tsunami yang mampu menyapu daratan, sehingga merubah daratan pantai dan penutupan lahan yang ada di pesisir daratan tersebut. Perubahan daratan pantai yaitu akibat tumpukan sedimen yang terbawa oleh gelombang maupun sedimen pantai yang terkikis dan terbawa oleh gelombang atau arus laut.

Wilayah pesisir Kecamatan Panimbang Kabupaten Pandeglang Provinsi Banten merupakan area yang terletak di Selat Sunda merupakan salah satu objek wisata pesisir yang banyak dikunjungi masyarakat JABODETABEK. Selain itu, wilayah Kecamatan Panimbang merupakan salah satu kawasan yang secara khusus dikembangkan untuk KEK (Kawasan Ekonomi Khusus), sehingga adanya upaya yang kuat pemerintah daerah dalam pengembangan infrastruktur.

Akan tetapi, secara geografis wilayah penelitian berada dekat dengan komplek gunung Anak Krakatau. Pada tanggal 22 Desember 2018 area penelitian terdampak tsunami, yang diduga disebabkan oleh faktor longsoran dasar laut akibat aktivitas Anak Gunung Krakatau. Peristiwa tersebut mengakibabtkan 267 orang meninggal, 1.143 orang luka-luka, 36 orang meninggal, dan 5.361 orang mengungsi (BNPB, 2018).

Wilayah penelitian merupakan berada pada zonasi tingkat kerawanan terhadap bahaya tsunami dan gempa. Akan 
tetapi, wilayah penelitian merupakan salah satu area wisata favorit masyarakat di Provinsi Banten karena adanya wisata pantai Tanjung Lesung, dan area Kawasan Ekonomi Khusus (KEK). Berdasarkan hal tersebut, penting dilakukan perencanaan tata ruang berbasis bencana.

Pada konsepsi penataan ruang, penggunaan lahan dan kaitannya dengan kegiatan perekonomian penduduk diatur dalam sistem penataan ruang wilayah. Sistem penataan ruang perlu memperhatikan informasi dan aspek kebencanaan di suatu daerah. Hal ini sesuai dengan amanat UU RI No.24 Tahun 2007 tentang Penanggulangan Bencana dan UU RI No. 26 Tahun 2007 tentang Penataan Ruang (Probosiwi \& Sudibyakto, 2013).

Hal tersebut dilakukan sebagai upaya mitigasi dalam penanggulangan risiko bencana. Berdasarkan hal tersebut, penting untuk memetakan perubahan penggunaan lahan wilayah penelitian pasca bencana tsunami Tahun 2018 sebagai rekomendasi perencanaan tata ruang berbasis informasi kebencanaan sesuai UU RI No.24 Tahun 2007 tentang Penanggulangan Bencana dan UU RI No. 26 Tahun 2007 tentang Penataan Ruang .

\section{METODE PENELITIAN Waktu dan Lokasi Penelitian}

Penelitain ini dilaksanakan pada Bulan April sampai Agustus 2019, yang dilaksanakan di Kecamatan Panimbang, Kabupaten Pandeglang, Banten. Lokasi penelitian disajikan pada Gambar 1.

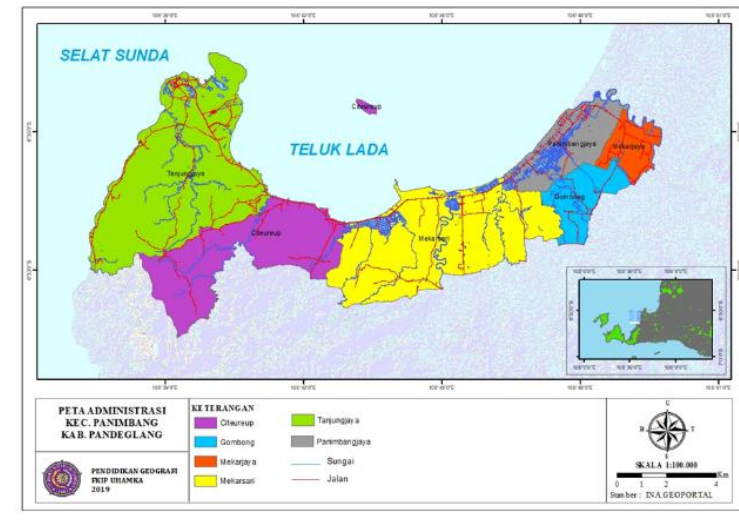

Gambar 1. Lokasi Penelitian

\section{Alat dan Bahan}

Alat dan bahan yang digunakan dalam penelitian ini beserta fungsinya disajikan pada Tabel 1.

Tabel 1. Alat dan Bahan Penelitian

\begin{tabular}{|c|c|c|}
\hline No & $\begin{array}{c}\text { Alat dan } \\
\text { Bahan }\end{array}$ & Fungsi \\
\hline 1 & GPS Garmin & $\begin{array}{l}\text { Merekam titik } \\
\text { koordinat }\end{array}$ \\
\hline 2 & $\begin{array}{l}\text { Perangkat } \\
\text { Lunak Arc-Gis } \\
10.6\end{array}$ & Analisis spasial \\
\hline 3 & $\begin{array}{l}\text { Kamera } \\
\text { DigitalCanon } \\
\text { A2300 }\end{array}$ & Dokumentasi \\
\hline 4 & Kuesioner & $\begin{array}{l}\text { Mengumpulkan } \\
\text { data primer }\end{array}$ \\
\hline 5 & $\begin{array}{l}\text { Perangkat lunak } \\
\text { DNRGPS }\end{array}$ & $\begin{array}{l}\text { Transfer data hasil } \\
\text { tracking GPS }\end{array}$ \\
\hline 6 & Drone & $\begin{array}{l}\text { Memotret } \\
\text { Penggunaan Lahan } \\
\text { Pasca Tsunami }\end{array}$ \\
\hline 7 & $\begin{array}{l}\text { Peta Rupa } \\
\text { Bumi }\end{array}$ & $\begin{array}{l}\text { Administrasi } \\
\text { Wilayah Penelitian }\end{array}$ \\
\hline 8 & $\begin{array}{l}\text { Data Citra } \\
\text { Sentinal }\end{array}$ & $\begin{array}{l}\text { Interpretasi Data } \\
\text { Penggunaan Lahan } \\
\text { Sebelum Tsunami }\end{array}$ \\
\hline
\end{tabular}

\section{Jenis Penelitian}

Jenis penelitian ini merupakan penelitian survey, yaitu penelitian yang sumber data berdasarkan data hasil survey lapangan terkait analisis perubahan penggunaan lahan sebelum dan sesudah kejadian tsunami Selat Sunda Banten Tahun 2018. Selanjutnya, hasil analisis perubahan 
penggunaan lahan di deskripsikan terkait kesesuaian dengan Rencana Tata Ruang Wilayah Kabupaten Pandeglang, Provinsi Banten.

\section{Metode pengumpulan, pengolahan, dan Analisis Data}

Metode pengumpulan data dalam penelitian ini terdiri atas data primer dan data sekunder. Metode pengumpulan data berupa wawancara, dokumentasi, dan observasi. Data primer yang dikumpulkan dalam penelitian yaitu melalui survei lapangan untuk memperoleh data area perubahan penggunaan lahan akibat terkena tsunami, dan wawancara dengan masyarakat sebagai pendukung informasi. Data Sekunder dalam penelitian ini berupa data Peta Rupabumi, dan Data Citra Sentinal.

Pengolahan data yang dilakukan dalam penelitian ini yaitu pengolahan data sekunder dan primer. Teknik pengolahan data yaitu data Peta RBI, Citra Sentinal, dan hasil survei lapangan diolah menggunakan softwareArc Gis 10.6, untuk menghasilkan Peta Administratif, peta pra survei lapangan, dan peta penggunaan lahan secara temporal sebelum dan sesudah tsunami.
Metode analisis data dalam penelitian ini menggunakan analisis deskriptif. Metode analisis deskriptif digunakan karena berdasarkan teknik interpretasi data citra secara kualitatif menggunakan unsur-unsur interpretasi seperti pola, tekstur, asosiasi. Hal ini dilakukan untuk identifikasi penggunaan lahan wilayah penelitian, serta mendeskripsikan analisis hasil wawancara dan temuan di lapangan.

Metode untuk analisis tata ruang dengan cara melakukan review Rencana Tata Ruang Wilayah (RTRW) Kabupaten Pandegelang, secara struktur dan pola ruang berdasarkan Perda Kabupaten Pandeglang No. 3 Tahun 2011.

\section{HASIL DAN PEMBAHASAN \\ Penggunaan Lahan Wilayah Penelitian Sebelum Tsunami}

Penggunaan lahan wilayah penelitian menunjukkan bahwa terdapat penggunaan lahan danau/situ, empang, sungai, tambak, sawah, tanah kosong, semak belukar, rawa, tegalan, hutan, bukit pasir darat, bukit pasir laut, perkebunan, permukimaan, dan bangunan. Mayortitas penggunaan lahan wilayah penelitian yaitu sawah dan perkebunan (Gambar 2).

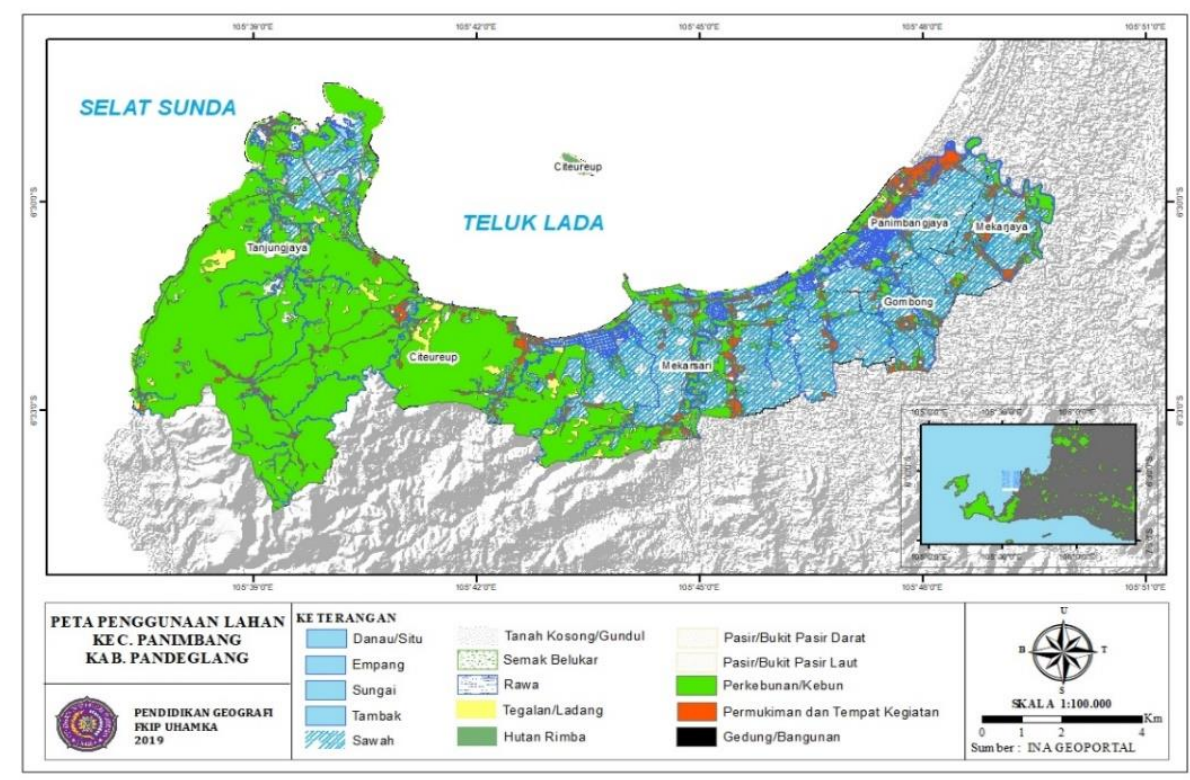

Gambar 2. Peta Penggunaan Lahan Wilayah Penelitian Sebelum Tsunami 
Kondisi penggunaan lahan wilayah penelitian mayoritas sawah dibagian barat wilayah penelitian, karena secara geologi wilayah tersebut merupakan batuan lunak dan alluvial yaitu material hasil endapan laut atau sungai. Kondisi tanah aluvial umumnya mengandung banyak mineral sehingga subur untuk pertanian. Selain itu, pada bagian barat secara kemiringan lereng dan elevasi merupakan area datar, hal ini mendukung untuk system irigasi sebagai pengairan. Untuk area kebun mayoritas berada pada Desa Tanjungjaya yang secara litologi merupakan batuan keras dan kemiringan lereng 4-350. Kondisi tersebut mengakibatkan lahan pada Desa Tanjungjaya mayoritas dimanfaatkan untuk perkebunan atau hutan yang didominasi oleh tanaman keras.

Wilayah penelitian merupakan area pesisir dan kawasan wisata, sehingga penggunaan lahan sekitar pesisir pantai mayoritas merupakan permukiman nelayan. Kawasan pemukiman nelayan mayoritas terletak di bagian barat wilayah penelitian (Gambar 3). Selain itu, diarea pesisir wilayah penelitian khususnya Desa Citeurup dan Tanjungjaya atau kawasan Tanjung Lesung dimanfaatkan sebagai resort, dan objek wisata (Gambar 4).

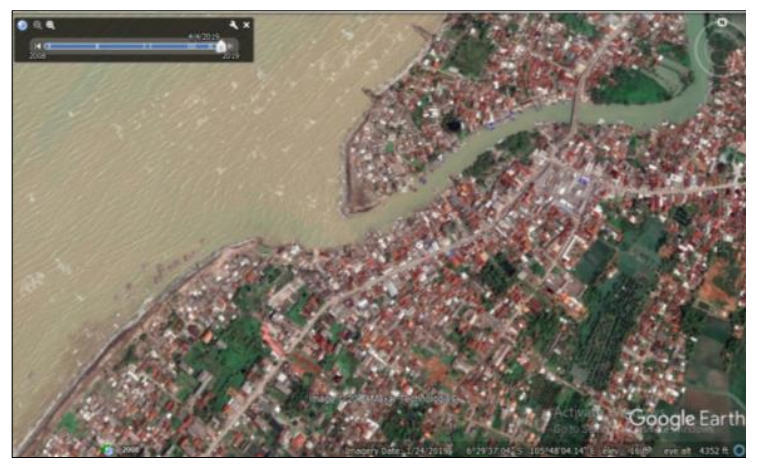

Gambar 3. Kawasan pemukiman di wilayah penelitian

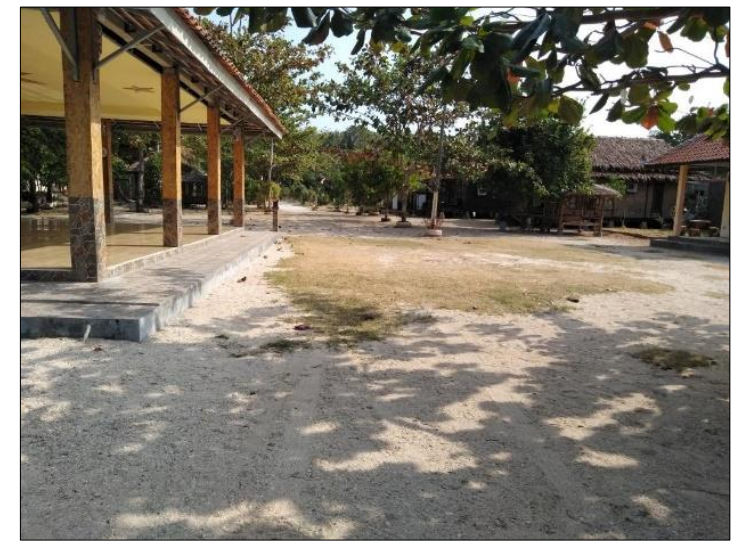

Gambar 4. Contoh Kawasan resort pesisir pantai

\section{Penggunaan Lahan Wilayah Penelitian Sebelum Pasca Tsunami}

Kejadian tsunami Banten

Desember Tahun 2018 berdampak pada lingkungan pesisir pantai wilayah penelitian, yaitu adanya perubahan penggunaan lahan. Perubahan penggunaan lahan merupakan peralihan suatu bentuk dan lokasi penggunaan lahan yang lama menjadi yang baru (Kusrini, Suharyadi, \& Hardoyo, 2011). Perubahan yang terjadi di wilayah penelitian terutama terjadi diarea pesisir pantai, karena faktor gelombang tsunami yang mengakibatkan hilangnya atau rusaknya suatu bangunan. Perubahan yang terjadi diwilayah penelitian yaitu hilangnya atau berkurangnya jumlah pemukiman yang terdapat dibeberapa lokasi area pesisir, sehingga berubah menjadi lahan kosong atau semak belukar (Gambar 5).

Berdasarkan Gambar 5 merupakan representasi area pemukiman nelayan pinggir pantai yang terkena tsunami, akan tetapi penduduk masih tetap bermukim di lokasi terkena tsunami. Selain merusak kawasan pemukiman, tsunami Banten tahun 2018 mengakibatkan perubahan dan kerusakan pada kawasan resort (Gambar 6 dan 7). 


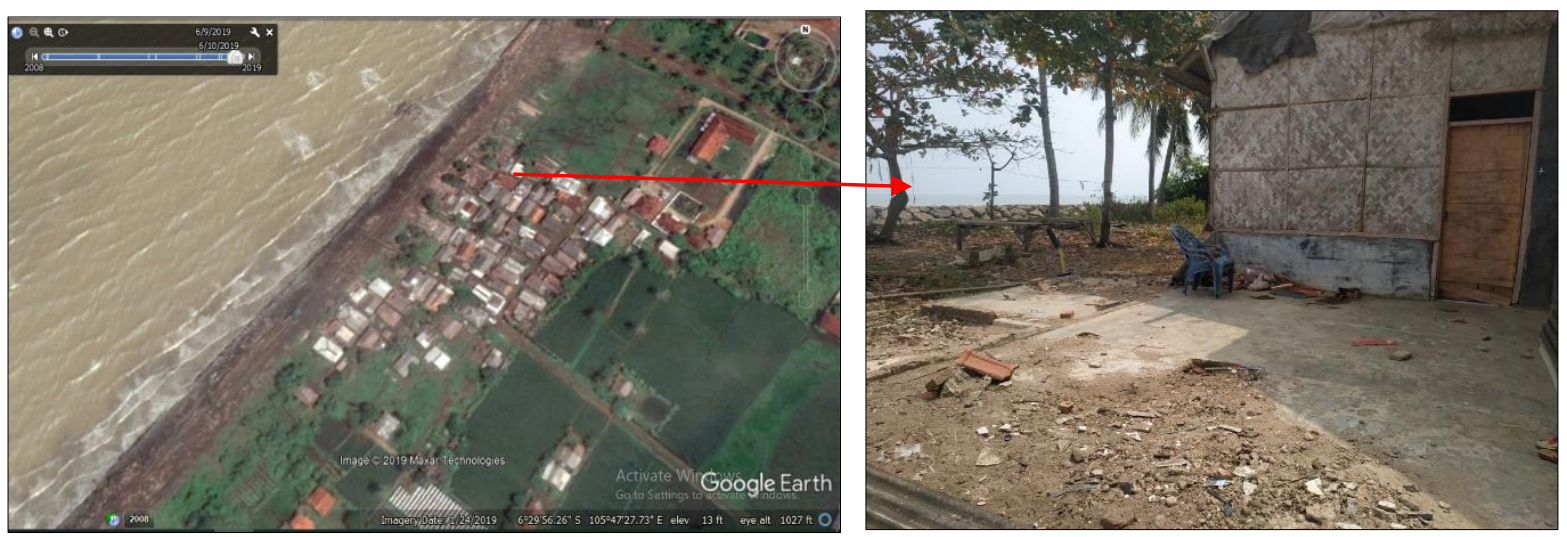

Gambar 5. Bangunan rumah terdampak tsunami

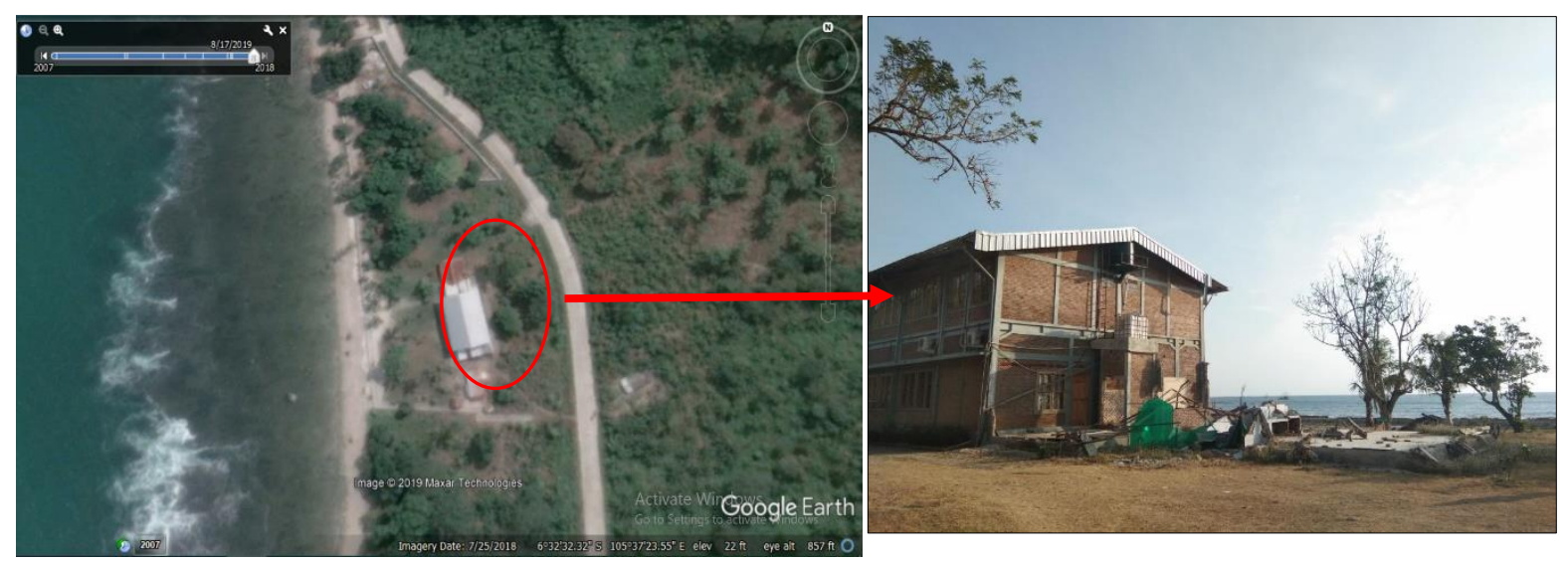

Gambar 6. Dampak tsunami terhadap resort di area pesisir Kecamatan Panimbang

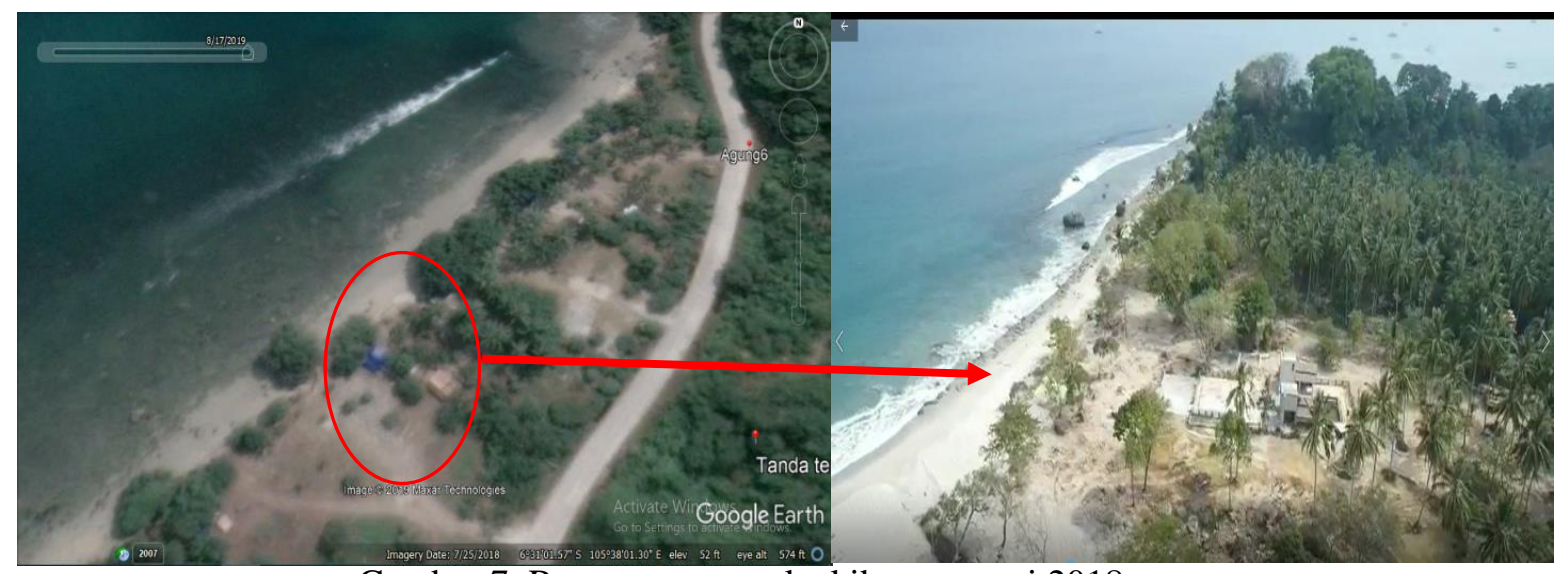

Gambar 7. Resort yang rusak akibat tsunami 2018

Berdaskan Gambar 6 dan 7 banyak investor untuk mendirikan menunjukkan bahwa pasca kejadian kawasan resort, homestay, dan hotel di tsunami 2018 selain merusak dan area pinggir pantai. Adanya bencana menghilangkan bangunan pemukiman, tsunami berdampak pada rusaknya berdampak juga pada rusaknya kawasan bangunan resort, homestay, dan hotel, resort di Kecamatan Panimbang. Kawasan sehingga menambah tinggi kerugian Tanjung Lesung merupakan area eksotis ekonomi akibat tsunami. Akan tetapi, hasil wisata pantai di Provinsi Banten, sehingga survey lapangan menunjukkan bahwa 
bangunan resort yang mengalami kerusakan akibat tsunami telah dilakukan perbaikan oleh pengembang wisata. Kondisi tersebut menunjukkan bahwa meskipun lokasi penelitian teridentifikasi sebagai area rawan bencana gempa, banjir, dan tsunami para pengembang masih tetap mempertahankan area pesisir wilayah penelitian sebagai investasi objek wisata. Selain itu, akibat tsunami yang merusak pemukiman warga di area pesisir pantai, sehingga memunculkan kawasan pemukiman baru atau hunian sementara di Desa Tanjungjaya (Gambar 8).

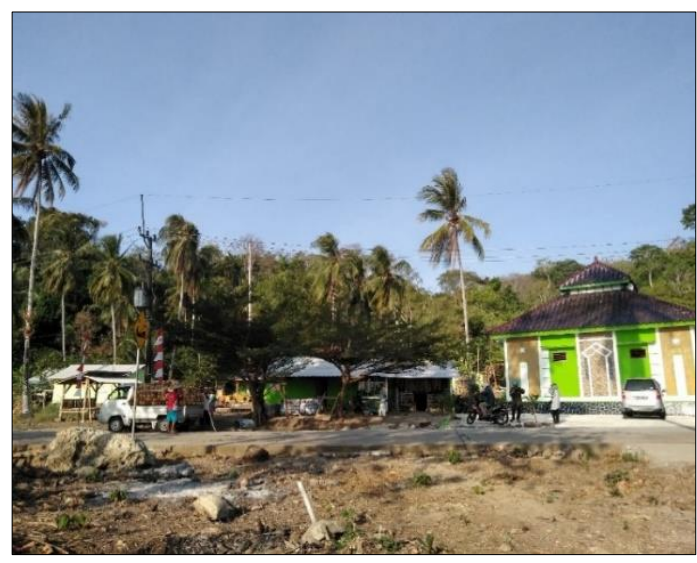

Gambar 8. Kawasan Hunian Semenatara Korban tsunami Selat Sunda Banten

Gambar 8 merupakan area bangunan hunian sementara untuk korban tsunami yang direlokasi karena rumah hunian mereka mengalami kerusakan atau hilang. Akan tetapi, lokasi hunian sementara yang didirikan masih tetap dekat dengan area pesisir pantai dengan jarak \pm 150 meter dari pantai. Kondisi tersebut menunjukkan bahwa Hunian Sementara yang digunakan masyarakat saat ini masih belum aman dari ancaman tsunami.

\section{Rencana Tata Ruang Wilayah Kecamatan Panimbang}

Rencana tata ruang wilayah (RTRW) Kecamatan Panimang di analisis berdasarkan RTRW Kabupaten
Pandeglang, yaitu dokumen Perda Kabupaten Pandeglang No. 3 Tahun 2011 tentang Rencana Tata Ruang Wilayah Kabupaten Pandeglang Tahun 2011-2031. Berdasarkan hasil peninjauan dokumen RTRW Kabupaten Pandeglang pasal 33 menunjukkan bahwa Kecamatan Panimbang merupakan area konservasi mangrove. Hal ini menunjukkan bahwa jika berdasarkan Perda wilayah pesisir pantai Kecamatan Panimbang di zonasikan sebagai kawasan mangrove. Kondisi di lapangan area pesisir pantai digunakan sebagai kawasan pemukiman dan wisata. Untuk itu, jika kawasan pesisir pantai dijadikan sebagai area konservasi mangrove dapat mengurangi potensi risiko korban jiwa dan kerugian jika terjadi ancaman tsunami.

Berdasrkan Perda Kabupaten Pandeglang No. 3 Tahun 2011 pasal 34 wilayah penelitian merupakan rawan bencana banjir, sehingga tahapan penanggulangan terfokus pada banjir. Akan tetapi, fakta di lapangan menunjukkan bahwa wilayah penelitian rawan juga terhadap bencana geologi seperti tsunami dan gempa, sehingga RTRW harus di analisis juga berdasarkan bencana tsunami dan gempa. Sebagai contoh, penataan penggunaan lahan dikawasan pesisir dengan pemberian zonasi minimum jarak lokasi pemukiman dengan bibir pantai. Hasil survey di lapangan di temukan papan informasi larangan pendirian bangunan di area pesisir, akan tetapi kondisi dilapangan masih banyak pemukiman diarea pesisir.

Berdasarkan Perda Kabupaten Pandeglang No. 3 Tahun 2011 pasal 39 dan 40 wilayah penelitian merupakan area pertanian dan perikanan. Kondisi tersebut didasarkan kondisi fisik penelitian yang merupakan area pesisir, sehingga potensial untuk pertanian dan perikanan. Penggunaan lahan perikanan dan pertanian ditemukan di area sepanjang pinggir pantai wilayah penelitian, hal ini karena aktivitas 
perikanan tidak dapat lepas dari lokasi pantai seperti pelelangan ikan. Secara tata ruang berbasis bencana aktivitas kerja dengan tempat tingal memiliki pengaruh berbeda dengan dampak suatu bencana. Hal ini bermaksud jika lokasi pekerjaan para nelayan di area pesisir karena aktivitas penangkapan ikan di laut dapat mengurangi risiko korban jiwa, jika pemukiman nelayan jauh dari pesisir pantai atau $>300$ meter dari bibir pantai. Akan tetapi, kondisi di lapangan mayoritas para neleyan memiliki tempat tingal di area pinggir pantai. Untuk itu, perlu penataan tata ruang terkait zonasi pemukiman nelayan yang terletak pada zona aman dari tsunami.

Berdasarkan Perda Kabupaten Pandeglang No. 3 Tahun 2011 pasal 43 wilayah penelitian merupakan area kawasan wisata. Adanya kenampakan fisik pantai dan ekologi yang menarik khususnya di area Tanjung Lesung, mengakibatkan wilayah penelitian sebagai daya tarik untuk objek wisata. Kondisi banyaknya wisatawan yang berkunjung di wilayah penelitian mengakibatkan banyaknya pembangunan resort, hotel, dan homestay. Temuan di lapangan banyak pembangunan resort, hotel, dan homestay berada di dekat pantai. Wilayah penelitian memiliki kerawanan terhadap ancaman tsunami, untuk itu penting dilakukan penataan ruang terkait zonasi pendirian resort, hotel, dan homestay yang berada pada jarak tertentu dari bibir pantai. Hal ini sebagai upaya untuk mitigasi bencana untuk mengurangi risiko korban jiwa. Sebagai salah satu contoh temuan dilapangan, homestay yang terletak di pinggir pantai dan mengalami kerusakan akibat tsunami, tetapi dilakukan perbaikan ulang dan tetap dilokasi yang sama. Jika kawasan resort atau hotel tetap terbangun dikawasan pesisir, maka penting menerapkan ketentuan bangunan tangguh terhadap tsunami.
Berdasarkan Perda Kabupaten Pandeglang No. 3 Tahun 2011 pasal 47 wilayah penelitian merupakan kawasan strategis pertumbuhan ekonomi, dan kawasan startegis kabupaten. Hal ini dikarenakan wilayah penelitian khususnya yaitu Tanjung Lesung merupakan salah satu kawasan yang secara khusus dikembangkan untuk KEK (Kawasan Ekonomi Khusus) untuk zona pariwisata menurut Peraturan Pemerintah Nomor 26 Tahun 2012. Pada umumnya kawasan ekonomi khusus merupakan kawasan yang mendapat prioritas khusus oleh pemerintah dalam pembangunan infrastruktur. Kondisi wilayah penelitian yang potensi terhadap ancaman tsunami, sehingga dalam penggembangan wilayah dan penentuan infrastuktur harus meninjau kesesuaian dengan kondisi bencana wilayah penelitian. Sebagai contoh, pendirian bangunan pengungsian atau tempat evakuasi, dan bagunan penahan gelombang.

\section{KESIMPULAN.}

Wilayah Kecamatan Panimbang, Kabupaten Pandeglang, Provinsi Banten merupakan area yang rawan terhadap tsunami. Dampak tsunami mengakibatkan kerusakan pemukiman dan lingkungan, korban jiwa, dan kerugian. Penyusunan rencana tata ruang berbasis bencana tsunami merupakan penting, sebagai upaya mitigasi bencana untuk mengurangi risiko. Hasil penelitian menunjukkan bahwa penggunaan lahan sebelum dan sesudah terjadinya tsunami wilayah penelitian adanya perubahan, khususnya diarea pesisir Panimbang. Perubahan yang terjadi teridentifikasi adanya kawasan pemukiman yang hilang, kawasan wisata dan resort yang rusak, dan memunculkan adanya kawasan Hunian Sementara. Desa yang mengalami signifikan perubahan yaitu Desa Tanjungjaya.

Berdasarkan Perda Kabupaten Pandeglang No. 3 Tahun 2011 wilayah 
penelitian merupakan kawasan konservasi mangrove, bencana banjir, pertanian dan perikanan, wisata, dan kawasan strategis pertumbuhan ekonomi, dan kawasan startegis kabupaten. Berdasarkan hal tersebut, tidak teridentifikasi wilayah penelitian sebagai kawasan bencana geologis atau rawan tsunami, untuk itu tidak tergambarkan rencana tata ruang wilayah penelitian berbasis tsunami.

\section{DAFTAR PUSTAKA}

Kusrini, Suharyadi, \& Hardoyo, S. R. (2011). Perubahan Penggunaan Lahan dan Faktor yang Mempengaruhinya di Kecamatan Gunungpati Kota Semarang. Majalah Geografi Indonesia, 25(1), 25-40. https://doi.org/10.22146/mgi.13358

Probosiwi, R., \& Sudibyakto. (2013). Manajemen Risiko Tsunami Untuk Penataan Ruang. Jurnal Teknosains, 2(2), 71-158.

Surmayadi, M. (2012). Evaluasi Risiko Bencana Tsunami Kabupaten Banyuwangi Provinsi Jawa Timur. Bandung: Pusat Vulkanologi dan Bencana Geologi.

Tejakusuma, I. G. (2005). Tsunami, Analisa Pasca Bencana Aceh (Vol. 10, pp. 18-21). Vol. 10, pp. 18-21.

Yudhicara, \& Budiono, K. (2008). Tsunamigenik di Selat Sunda: Kajian terhadap katalog Tsunami Soloviev. Jurnal Geologi Indonesia, 3(4), 241251.

https://doi.org/10.17014/ijog.vol3no 4.20086

Peraturan Daerah Kabupaten Pandeglang No. 3, Tahun 2011 Tentang Rencana Tata Ruang Wilayah Kabupaten Pandeglang Tahun 2011-2031.
Undang- Undang Republik Indonesia No.24 Tahun 2007 tentang Penanggulangan Bencana.

Undang- Undang Republik Indonesia No. 26 Tahun 2007 tentang Penataan Ruang. 